\title{
A vadiagem e sua inscrição nos corpos
}

\author{
Vagrancy and its bodily imprint
}

\author{
Lilia Moritz Schwarcz \\ Professora do Departamento de Antropologia da Universidade de São Paulo \\ Rua Salvador de Mendonça, 95 \\ 01450-040 São Paulo — SP \\ lilia.ms@uol.com.br
}

"O arquivo nasceu da desordem."

Arlete Farge

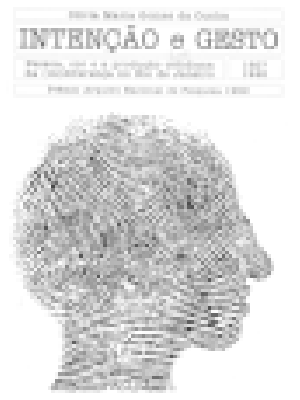

Olívia Maria Gomes da Cunha

Intenção e gesto.

Pessoa, cor e a produção cotidiana da (in) diferença no Rio de Janeiro. 1927-1942

Rio de Janeiro, Arquivo Nacional, 2002, 608p.

\section{Sobre a eficácia da classificação}

$\mathrm{E}$ ngana-se aquele que pensa que tudo que a memória faz é lembrar. Os arquivos estão repletos de lembranças, mas também devastados por silêncios e omissões: assim como é função lembrar, faz parte do ofício esquecer.

No caso brasileiro tal lógica não poderia ser diferente. Se a memória sempre fez parte - na nossa cultura - dessa prática do registro, a oficialização de tal ato, e sobretudo das práticas criminais, tem data e lugar. Foi no ano de 1906 que se inaugurou no país uma nova política de identificação para fins criminais, assim como se formularam as primeiras críticas a seu uso extensivo. Por sinal, fazia parte desse debate o uso da câmara fotográfica — as famosas 'chapas' tiradas nas delegacias, que tinha um caráter oposto à voga dos daguerreótipos e das cartes de visite. Se o retrato era fartamente utilizado pelas elites brasileiras - que viam nele uma maneira de perpetuar uma certa memória que dignificava e falava da 'civilização entre nós' —, radicalmente diferente era seu uso para fins judiciais. Neste caso instalava-se uma política de 'humilhação e vexame', ou então um certo "estigma da desonra", como tão bem denominou Barata Ribeiro.

Mas a fotografia é só pretexto para começo de análise. Ela seria crescentemente substituída pela impressão digital, que se tornaria obrigatória como identificação em 1932. Com efeito, não foram poucas as técnicas de identificação criminal, assim como tornavam-se sofisticados os aparatos científicos, jurídicos e policiais que protegiam o Estado da ação dos indivíduos criminosos. No entanto, se muitos foram os registros, mais interessa pensar na sua eficácia simbólica e em sua rápida disseminação nas capitais brasileiras, nas primeiras décadas do século XX. Nesse contexto criavam-se a figura do 'cidadão criminoso' e a imagem de um grande arquivo que corporificava uma nação utópica, uma vez que seriada, classificada e nomeada.

Em torno dessa questão desenvolve-se a obra de Olívia Maria Gomes da Cunha, que faz dos arquivos de identificação um mote para pensar na produção da memória que se constrói sobre certos sujeitos sociais. Para tanto, elegeu como objetos de estudo os discursos e as práticas de 
identificação criminal voltados à prevenção da 'vadiagem' e à repressão dos vadios, na década de 1930. A intenção não é tanto produzir uma história da política de repressão à vadiagem, nem muito menos uma genealogia das transformações institucionais. O objetivo foi, antes, pensar como os discursos sobre a cientifização dos mecanismos de identificação criminal estiveram ligados a determinadas concepções e acabaram por criar imagens e representações a respeito dessa sociedade e dos indivíduos criminalizados que a compunham. Por isso 'vadiagem' aparece nesse livro menos como realidade e mais como categoria de acusação, utilizada e acionada em diferentes situações.

A idéia é, assim, buscar nas práticas de identificação não tanto seu lado pragmático, mas sobretudo esse 'ritual de rotulação' e de impressão de identidades criminais. Em questão está, portanto, a eficácia. Afinal, como diz Lévi-Strauss em 'O feiticeiro e sua magia', pouco se deve perguntar sobre o uso de poções, cânticos e outras práticas do xamã. O feiticeiro cura quando virou objeto de consenso: a sociedade sabe (e quer) que ele cure, o doente crê na cura e, por fim, o próprio feiticeiro acredita na sua mágica. Também Marc Bloch, em livro premonitório datado de 1924, falava do poder taumatúrgico dos reis medievais franceses e ingleses e concluía ter feito não uma história do milagre, mas uma história da 'vontade do milagre'.

Trata-se, então, de pensar na lógica do consenso e em como, nesse caso, a 'vontade de identificar' e o consenso que se cria em torno da identificação falam mais do que um punhado de medidas mais imediatas. A ordem nasceu da desordem e da vontade de classificar.

\section{Do texto: entre esses tantos 'vadios'...}

A hipótese central de Intenção e gesto é, portanto, a idéia de que a identificação de sujeitos considerados vadios refletia (e produzia) uma determinada representação do conjunto de indivíduos que compunham esse país; tudo isso em meio a um contexto de fervoroso debate sobre a construção da nação. Por isso mesmo dois projetos se afirmavam e, apesar de distintos, eram implementados simultaneamente pelo Estado: o da individuação, de um lado, e a formação nacional, de outro.

Mas toda investigação tem um locus, e o dessa pesquisa foram os processos de vadiagem instaurados pela $5^{\underline{a}}$ Pretoria Criminal, instância jurídica que na época se subordinava à Procuradoria Geral do Distrito Federal. No entanto, se o local parecia evidente, menos clara era a possibilidade de delimitar o que significava um indivíduo 'suspeito', entre o final dos anos 1920 e meados da década seguinte. E assim o resultado da pesquisa não são propriamente os indivíduos acusados de vadiagem, mas a política de reiteração na caracterização e identificação de vadios, produzida pelas instituições policiais.

Aí estão não só o paradigmático Febrônio Índio do Brasil, mas os menos conhecidos João da Mota, a Jove, o Raimundo, o moleque Felix ou os Moleques 31, 17, 30, 4..., Juvêncio, Gaudino, Constantino, Peixerinho, Isaltino e tantos outros reconhecidos e identificados nos processos. Aí estão, também, as estratégias de qualificação e um certo arranjo classificatório dos termos, que implicava em insistir em determinados estigmas 
e traços próprios aos acusados; entre eles, a cor. Da leitura dos processos de vadiagem chega-se a uma certa identificação, quase que rotineira, delineada para além das práticas mais científicas. O inusitado, porém, é que nesse caso a 'eficácia' não está exatamente na criminalização nem muito menos no volume de condenações. A originalidade da obra de Olívia Cunha está justamente em interpretar os gestos e verificar como se conformava uma certa identidade adscrita às pessoas consideradas 'suspeitas' e sob determinados critérios. Mas depois de delineados os tantos 'moleques' e vadios, a autora passa para o outro lado. É o momento de adentrar — bem-acompanhados - o mundo dos vetustos doutores de jaleco branco.

\section{Ao contexto: identificando}

Se em um primeiro momento convivemos com 'o universo dos vadios', a partir da segunda parte do livro o discurso dos próprios policiais sobre seu ofício e dos intelectuais 'competentes' aparecem como campo de reflexão. Para tanto a autora recorre a livros e periódicos da década de 1930, buscando as correlações entre as idéias de ciência e arte e sua utilização na conformação de uma nova imagem para a Polícia Civil do Distrito Federal depois da reforma de 1933.

Em primeiro lugar, busca compreender como a noção de ciência foi incorporada ao discurso dos policiais, que assim nomeavam seu ofício e prática e configuravam um projeto institucional. O que se verifica é o surgimento de uma polícia científica que tinha como objeto melhor identificar o criminoso. A idéia era, também, divulgar um conhecimento a respeito daqueles indivíduos sob quem deveriam pairar a observação e a suspeição; ou melhor, sob os sujeitos 'passíveis de observação'. E nesse sentido a fisionomia se transformava em critério certeiro.

Os exemplos são muitos, e detalhados, e não há como parar em um só. O que importa é que a nação se transformava rapidamente em metáfora de corpo biológico, cujo modelo poderia ser não só observado e descrito como ajustado e adequado aos processos civilizatórios estimados pelas elites intelectuais. Nesse movimento, que leva à eleição de modelos de identidade utilizados na construção do homo criminalis brasileiro, a associação entre antropologia, medicina e criminologia mostrou-se fundamental, sobretudo na conformação desses 'objetos' de uma política de Estado. Esse é o período em que se afirmam o discurso da eugenia e as tentativas de classificar e conceituar, por oposição à mera idéia de raça.

E aí entramos em outra seara. Nesse momento do livro, Olívia Cunha se detém na investigação acerca do poder disciplinar das práticas identificatórias e no papel decisivo da reforma penal implementada pelo Estado autoritário. Estarão também presentes as classificações originalmente propostas pelos médicos acerca de uma assim chamada identidade criminal. Nomes como Nina Rodrigues, Afrânio Peixoto, João Batista Lacerda, Roquete Pinto, Álvaro Fróes da Fonseca, Oliveira Viana, Renato Kehl e Alexandre Tepedino desfilam pelas páginas de Intenção e gesto, constituindo, de forma inexorável, o criminoso assim como a 
criminalidade. O paradoxo é que ao propor uma 'ciência do individual' e da própria 'personalidade', essas elites acabaram buscando registros que imaginavam não mais distinguir povos e grupos étnicos, mas antes indivíduos marcados pela herança racial.

Mas não é só e ponto final. Após ter feito essa longa viagem a autora se volta para o tema da vadiagem, verticalizando sua análise na obra de Jimenez de Ássua, Evaristo de Morais, Vicente Piragibe, Ari Franco, Nilton Barcelos, entre tantos outros que se fizeram a difícil questão: afinal, como definir o vagabundo? Significativa é a resposta de Piragibe, que, apesar de se utilizar de um enfoque sociológico, incorre em noções médicas como a de contágio:

A vagabundagem é em regra um sintoma denunciador de um mal que precisa ser cuidado: de ordinário resulta da criança orfanada, criada ao léu, vivendo do favor aqui e ali, tolerada por parentes ou suportada como um peso por estranhos, humilhada a cada hora, enganando a fome com migalhas, carregando enfim a pesada cruz da esmola ... (p. 415).

Mais do que uma definição, Vicente Piragibe parecia falar do grande número de menores detidos pela polícia e investir em uma interpretação diferente de outras à época.

Enquanto as teorias caracterizam, os quadros referentes aos presí-dios do Distrito Federal vão costurando uma representação que associa a vadiagem à população de cor. O fato é que se dá um processo contínuo de acumulação de conhecimentos sobre a vadiagem que vai se constituindo como campo jurídico. De uma maneira geral, a conclusão da autora demonstra que a natureza discursiva que embasou as primeiras medidas jurídicas, inspiradas por variadas interpretações da vadiagem, acabou por pautar-se pela tônica do esquecimento. As dádivas concedidas em maio de 1888 eram repassadas por uma política que implicou em identificar e olvidar. $\mathrm{Na}$ associação entre vadios e homens de cor rearranjavam-se as teorias, especificavam-se os lugares da criminalização, porém, mais uma vez, esquecia-se de uma vasta parte da população, agora com direito à igualdade formal.

\section{Voltando ao texto: afinal, quem são esses vagabundos?}

Hora de voltar às 'carreiras criminais', identificadas por Olívia Cunha no começo do livro e em grande parte produzidas pela ação de policiais. Aí estão novamente as histórias de indivíduos presos por vadiagem que acabaram sendo examinados e observados de uma maneira particular no Gabinete de Identificação. Retornar a elas, depois desse longo passeio, significa encontrar nova densidade na mesma narrativa, agora adornada por tantas teorias e modelos científicos. E é nesse momento que a autora introduz os 'serviços' do Laboratório de Antropologia Criminal e volta sua atenção para a atuação desse instituto. Reaparecem então, brevemente, os tantos Febrônios, Isaltinos, Moleques 31 e outros 'vagabundos e criminalizados' que emprestam seus nomes às fichas. 
Nas análises do laboratório tentava-se pôr em prática uma leitura científica das aparências, antes relegadas à linguagem vulgar do lugarcomum. Ao realizar tal tarefa, estabeleciam-se ligações entre as 'impressões' e o 'conhecimento', resultados inesperados da releitura interessada das teorias e metodologias importadas. Pois Olívia Cunha não se limita a esquadrinhar a produção nacional; investe nos modelos estrangeiros, que tanto sucesso fizeram entre as 'elites científicas' do país. Nesse processo, o aparente vira marca de identidade, apesar das dificuldades, muitas vezes encontradas, de tradução. O resultado é o indivíduo anti-social, a figura do vadio que surge como um continuum entre corpo e comportamento.

Assim, é o corpo que se transforma no território privilegiado para os discursos sobre as diferenças individuais e sociais, mais especificamente transformados em modelos racialistas. Por isso mesmo, conclui Olívia Cunha, a invenção do vadio "resultou em uma inversão do princípio aparentemente simples: quando a hierarquia colonial se fez presunção igualitária” (p. 527). Assim como as categorias de pertencimento e identificação são culturalmente construídas, a vadiagem é também ausência e presença. Silêncio na falta de identificação que carrega; presença na mensagem que denota. E é a aparência, e não tanto a marca (como queria Oraci Nogueira) ou o fenótipo, que constitui essa memória. A cor da pele marca sobre o corpo não tanto uma origem mas uma memória social. Não é somente o passado escravocrata ou a degradação do trabalho manual (tantas vezes desacreditado) que identificam esse território, mas sobretudo a reatualização do que esse passado contamina no próprio presente. O passado reside no silêncio, mas o corpo é que se comporta como arquivo da nação e relembra mesmo quando se quer esquecer.

\section{Juntando as fichas}

Tempo de acabar. Difícil mesmo é a tarefa de resenhar um livro enciclopédico como esse. Por isso limitei-me a anotar os caminhos e a recuperar as grandes conclusões. No entanto, na leitura da obra, uma certa estrutura implícita foi se afirmando. Mesmo sem o citar explicitamente, arrisco-me aqui a dizer que, na construção do livro e de seu argumento, Olívia Cunha parece ter estabelecido um paralelo com a famosa metodologia de Robert Darnton, em O grande massacre de gatos, que implica em ir "do texto ao contexto voltando ao texto".

Com efeito, Intenção e gesto começa apresentando seus personagens - o texto - resume longamente o debate nas instituições científicas e elites especializadas, nacionais e internacionais - o contexto para depois retornar ao texto — os próprios vadios, abandonados no decorrer da leitura. Com isso não se fica restrito aos casos isolados, mas é possível enquadrá-los em contextos discursivos mais amplos, que ajudam nas suas definições.

No entanto essa imensa vantagem pode também ser uma armadilha. Em primeiro lugar, o foco das fontes oscila durante o livro, e muitas vezes se perde o prumo de onde, com quem e quando se fala. Por outro lado, por mais que as fontes sejam 'viciadas', como bem ensina 
Carlo Ginzburg em 'O inquisidor como antropólogo', o medo de desconfiar dos documentos não pode nos levar a "jogar fora o bebê com a água do banho". É possível ler por sobre 'os ombros do inquisidor' e recuperar, por vezes, dialogias, no sentido de Bakhtin: verdadeiros debates que se travam entre inquisidor e sua vítima.

Paradoxalmente, é esse diálogo que pouco se apresenta no texto de Olívia Cunha. O painel, como tentei mostrar, é monumental, e o leitor sai totalmente informado sobre as teorias e os debates da época. Porém, com tanto contexto intelectual chegamos aos documentos muito armados, e as personagens acabam falando muito pouco, assim como raras vezes interferem diretamente na análise, feita de fora para dentro.

Se, como diz o mesmo historiador Carlo Ginzburg, a cultura é uma "jaula flexível", é possível atentar para a jaula sem esquecer do seu lado mais (ou um pouco) flexível. Talvez seja pedir muito, uma vez que a autora traça um panorama absolutamente invejável das teorias e instituições da época. Mas quem sabe seja hora de dar mais espaço aos 'corpos esquecidos' e tão procurados nesse livro. Moleques, Febrônios, Peixeirinho e tantos outros podem ser identificados nas políticas de época, mas talvez valha a pena 'levar a sério' o que têm a dizer. Olívia Cunha 'leva a sério', e a todo momento, os seus vadios. São eles que informam a leitura e tensionam a análise. No entanto, muitas vezes o contexto se mostra absoluta e terminantemente definidor. E então parece difícil desorganizar a própria ordem. 